$13^{\text {th }}$ International Conference on

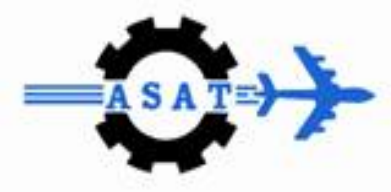

\title{
Estimation of the Relative Density for Honeycomb Panels Subjected to Blast
}

\author{
H. M El-Fayad*, M. M Abdel-Wahab ${ }^{*}$, H. M.Farag* and A. A El-Ashaal ${ }^{* *}$
}

\begin{abstract}
Sandwich panels give an optimum and proven tools to handle problems related to design and analysis of the structures subjected to blast load. The present work focuses on estimating the relative density of steel honeycomb sandwich panels. These panels can be applied on defense works, homeland security, banks and civilian industries intended to minimize the effects of accidental explosions. Sandwich constructions with metallic hexagonal honeycomb core are utilized in this paper due to its high specific strength and stiffness relative to its weight. Estimating the relative density of the metallic hexagonal honeycomb core based on single degree of freedom and the scaling dimensional and considering the dynamic factor contrived under transient dynamic loads resulted from detonating any amount of TNT at any stand-off distance. The strength and stiffness of simply support honeycomb core panels were evaluated based on boundary condition of strength and deformation. The proposed approach suggested controlling the safety design for those panels.
\end{abstract}

Keywords: Sandwich Panels, Honeycomb, Density, Blast Load

\author{
Abbreviations \\ TM5 : Technical manual \\ F.E.M : Finite element method \\ APDL : ANSYS Parametric Design Language \\ DOE : Design of Experiments
}

\section{Objective}

The primary objectives are to establish design procedures and chart techniques for smooth designing the sandwich panel subjected to blast load or estimating the resistance of the prefabricated sandwich panels.

\section{Introduction}

Some structures during their service life might be subjected to explosive loads. For example, industrial explosion accidents are causes of such events. Also some important infrastructure such as government buildings, embassy buildings, and bridges might be targets for a terrorist bombing attack. Understanding structural response to explosive loads is essential to protect critical infrastructure against explosions. Sandwich construction with hexagonal honeycomb core is the most widely used construction in sandwich construction. It has been proven to be

\footnotetext{
Egyptian Armed Forces, Egypt

** Professor. Director of Construction Research Institute, National Water Research Center, Egypt
} 
more effective in resisting blast loading. The use of sandwich panels might be an effective method to mitigate the damaging effects of blast loading on structural buildings. Sandwich construction with hexagonal honeycomb core is common structural members. It is a structural element which consists of thin-wall elements as shown in figure (1). Typical hexagonal honeycomb core is shown in figures (2) and (3). Sandwich construction is mainly used to obtain specific strength and stiffness, i.e. to obtain minimum weight of structural elements under the premises of design requirements. Since they have a high strength to weight ratio and excellent energy absorption capabilities under dynamic loading conditions, the core of the sandwich structure can sustain large deformations under a constant load, enabling it to absorb energy as shown in the Figure (4) [1]. A relative density of the sandwich panel subjected to blast loads will be discussed and determined using scaling dimensional.

\section{Methodology}

\subsection{Estimating the blast loads}

This section provides a rapid method to estimate the peak overpressure and the duration of the blast wave resulted from explosion of any spherical TNT charge. TM5 [2] provide an experimental design chart to calculate the positive phase shock wave parameters (duration and positive pressure) for a spherical TNT explosion in free air versus scaling distance $\left(\mathrm{Z}=\mathrm{R} / \mathrm{W}^{(1 / 3)}\right)$ where :

Z: The scaling distance.

$\mathrm{R}$ : The target distance from the explosion [ft].

W: The explosive amount [lb].

In the present study, the charts provided from TM5 were converted into four polynomials of order ten versus $(Z)$ for the easy use into the dynamic response calculation. The first polynomial is for estimating the peak over pressure, $\mathrm{P}$ [Psi] will be of the form:

$$
\begin{aligned}
\log (P) & =2.9267665-1.6622940 \log (Z)-0.88309316(\log (Z))^{2} \\
& +0.026782407(\log (Z))^{3}+0.52296827(\log (Z))^{4}+0.078522816(\log (Z))^{5} \\
& -0.20894177(\log (Z))^{6}+0.26836759(\log (Z))^{7}+0.0084835013(\log (Z))^{8} \\
& +0.0000082855449(\log (Z))^{9}-0.0000015187132(\log (Z))^{10}
\end{aligned}
$$

The three other polynomials for estimating the positive phase duration, $T_{d}[\mathrm{~ms}]$ had the form:

For: $0<Z<2.6$ :

$$
\begin{aligned}
\log \left(\mathrm{T}_{\mathrm{d}} /{ }^{\mathrm{W} 1 / 3}\right)= & -0.76047355+1.1372654 \log (\mathrm{Z})+3.3404647(\log (\mathrm{Z}))^{2} \\
& -0.60166015(\log (\mathrm{Z}))^{3}+17.186696(\log (\mathrm{Z}))^{4}+138.66359(\log (\mathrm{Z}))^{5} \\
& -45.686235(\log (\mathrm{Z}))^{6}-1488.6916(\log (\mathrm{Z}))^{7}-1580.1739(\log (\mathrm{Z}))^{8} \\
& +4088.5940(\log (\mathrm{Z}))^{9}+6422.6243(\log (\mathrm{Z}))^{10}
\end{aligned}
$$

For: $Z \in[2.6,5]:$

$$
\begin{aligned}
\log \left(\mathrm{T}_{\mathrm{d}} /{ }^{\mathrm{Wl} / 3}\right)= & +102.92473-1305.1188 \log (\mathrm{Z})+6914.2021(\log (\mathrm{Z}))^{2} \\
& -19460.924(\log (\mathrm{Z}))^{3}+29474.072(\log (\mathrm{Z}))^{4}-16283.437(\log (\mathrm{Z}))^{5} \\
& -20855.160(\log (\mathrm{Z}))^{6}+47875.291(\log (\mathrm{Z}))^{7}-40117.890(\log (\mathrm{Z}))^{8} \\
& +16129.822(\log (\mathrm{Z}))^{9}-2455.0256(\log (\mathrm{Z}))^{10}
\end{aligned}
$$


For: $Z \in[5,100]:$

$$
\begin{aligned}
\log \left(\mathrm{T}_{\mathrm{d}} /{ }^{\mathrm{W} 1 / 3}\right)= & +29.084164-199.77862 \log (\mathrm{Z})+528.58081(\log (\mathrm{Z}))^{2} \\
& -624.83222(\log (\mathrm{Z}))^{3}+121.44870(\log (\mathrm{Z}))^{4}+589.66850(\log (\mathrm{Z}))^{5} \\
& -819.77630(\log (\mathrm{Z}))^{6}+539.24999(\log (\mathrm{Z}))^{7}-200.19277(\log (\mathrm{Z}))^{8} \\
& +40.372773(\log (\mathrm{Z}))^{9}-3.4540186(\log (\mathrm{Z}))^{10}
\end{aligned}
$$

Table (1) shows the comparison between the pressure and time duration obtained by The TM5 and the present equations [1] and [2', 2", 2"' ] for four random values of scaling distance. The table shows that the resulting errors are less than $5 \%$, this result indicates that the polynomials can be used to estimate the pressure and positive phase duration of the air blast and approximately the transient triangular load form as shown in figure (5), then the transient load can be applied on the model using ANSYS [3] or AUTODYN [4] program.

\subsection{Eigen Value Problem of the Honeycomb Panels}

A general theory of hexagonal honeycomb core sandwich panels subjected to blast loads is not available. In general, the blast loads caused by a high-explosive detonation are complicated. Therefore, for the sake of simplicity of design, the following assumptions are made:

1. The panel is considered to be a simply hinged supported structure on all four edges when the blast waves interact with the panel.

2. The blast load can be simulated as a uniformly distributed transient load.

The dynamic behavior of the equivalent sandwich panels with solid panels has been investigated in this section. To convert the sandwich panels to an approximate equivalent solid plate, the relative densities of honeycomb was taken into account. Firstly the free vibration based on the frequencies and the modes shape of the plate has been discussed. figure (5) show a rectangular plate of length ( a), width (b), and thickness (h) subjected to an approximately uniform transient loads.

The transverse displacement (lateral deflection) $\mathrm{w}(\mathrm{x}, \mathrm{y}, \mathrm{t})$ of the natural surface of the plate in free vibration is governed by the differential equation, based on Kirchhoff theory [5]

$D \nabla^{4} w(\mathrm{x}, \mathrm{y}, \mathrm{t})+\rho \frac{\partial^{2} w(\mathrm{x}, \mathrm{y}, \mathrm{t})}{\partial \mathrm{t}^{2}}=0$

where: the biharmonic operator

$\nabla^{4}=\frac{\partial^{4}}{\partial x^{4}}+2 \frac{\partial^{2}}{\partial x^{2}} \frac{\partial^{2}}{\partial y^{2}}+\frac{\partial^{4}}{\partial y^{4}}$

$\rho$ : The mass density (mass per unit area).

And the bending stiffness or flexural rigidity of the plate

$$
D=\frac{E h^{3}}{12\left(1-\vartheta^{2}\right)}
$$


where:

E: young's modulus.

$\vartheta$ : Poisson's ratio.

A fundamental issue in free vibration analysis of plates is to solve the differential equation (3) subject to appropriate boundary conditions. By separation of variables, the transverse displacement of a plate can be expressed as

$w(x, y, t)=W(x, y) \cos (\omega t+\theta)$

where:

$\theta:$ An arbitrary constant.

$\mathrm{W}(\mathrm{x}, \mathrm{y})$ : Eigen function or mode shape.

$\omega$ : Natural frequency or Eigen value.

Substituting Eq. (6) into Eq. (3) yields the Eigen value problem of the plate

$\left(\frac{\partial^{4}}{\partial x^{4}}+2 \frac{\partial^{2}}{\partial x^{2}} \frac{\partial^{2}}{\partial y^{2}}+\frac{\partial^{4}}{\partial y^{4}}\right) W(x, y)-\frac{\rho \omega^{2}}{D} W(x . y)=0$

For simply supported plate along all edges, Navier, was assuming that the displacement as:

$W(x, y)=A \sin \frac{m \pi x}{a} \sin \frac{n \pi y}{b}$

where:

$\mathrm{m}$ and $\mathrm{n}$ : Are integers.

A: Nonzero constant.

The eq. (8) satisfies the following boundary conditions

At edge $\mathrm{x}=0$ or $\mathrm{x}=\mathrm{a}$

$$
w=0 \quad, \quad \frac{\partial^{2} w}{\partial x^{2}}=0
$$

At edge $y=0$ or $y=b$

$$
w=0 \quad, \quad \frac{\partial^{2} w}{\partial y^{2}}=0
$$

Substituting Eq. (8) into Eq. (7), yields the following characteristic equation

$\pi^{4}\left(\frac{m^{2}}{a^{2}}+\frac{n^{2}}{b^{2}}\right)^{2}-\frac{\rho \omega^{2}}{D}=0$

The roots of equation (9) are the natural frequencies of the plate, namely 
$\omega_{m n}=\pi^{2}\left(\frac{m^{2}}{a^{2}}+\frac{n^{2}}{b^{2}}\right) \sqrt{\frac{D}{\rho}}, \quad m, n=1,2, \ldots$

The mode shapes are given by equation (10), with $\mathrm{m}$ and $\mathrm{n}$ representing the number of half sine waves in the $\mathrm{x}$ and $\mathrm{y}$ directions, respectively.

The equivalent mass per unit area for the sandwich panel with equal faces $M_{e}$ will be in the form:

$M_{e}=\rho_{p} h_{e}=\rho_{p}\left(2 h_{f}+\rho_{c} \cdot h_{c}\right)$

where:

$\rho_{p}$ : The density of the material.

$h_{e}$ : The thickness of the equivalent plate

$h_{f}$ : The thickness of the sandwich plate face.

$h_{c}$ : The height of the sandwich core.

$\rho_{c}$ : The relative density of the sandwich core.

The relative density defined as the volume of material for one cell divided by the total volume of that cell. Then the relative densities of regular hexagonal honeycomb core [5]:

$\rho_{c}=\frac{8 t}{3\left(\sqrt{3} l+2 T_{C}\right)}$

And the relative densities of un regular hexagonal honeycomb core:

$\rho_{c}=\frac{7 t}{3\left(\sqrt{3} l+2 T_{C}\right)}$

As an example: assume the sandwich panel with un regular honeycomb core with dimensions: $(\mathrm{b}=140 \mathrm{~cm}, \mathrm{a}=260 \mathrm{~cm})$ and thickness equal to $(1 \mathrm{~cm}+18 \mathrm{~cm}+1 \mathrm{~cm}=20 \mathrm{~cm})$ with wall thickness equal to $\mathrm{Tc}=1 \mathrm{~mm}$, with the properties:

E: young's modulus $=2 \times 1011 \mathrm{pa}=2039432 \mathrm{~kg} / \mathrm{cm}^{2}=2.039432 \mathrm{E}+10 \mathrm{~kg} / \mathrm{m}^{2}$.

$\vartheta$ : Poisson's ratio $=0.3$

$l$ : Wall core length $=0.11547 \mathrm{~m}$.

$\rho_{p}$ : The density of the material $=7850 \mathrm{~kg} / \mathrm{m}^{3}$.

Then:

Bending stiffness $D=E^{*} h^{3} /\left(1-\vartheta^{2}\right) / 12=19910.6913 \mathrm{~kg} / \mathrm{m}$

$$
\begin{aligned}
& \rho_{c}=\frac{7 t}{3\left(\sqrt{3} \mathrm{l}+2 \mathrm{~T}_{\mathrm{C}}\right)}=\frac{7 \times 0.001}{3(\sqrt{3} \times 0.11547+0.001)}=0.01161 \\
& \mathrm{~h}_{\mathrm{e}}=2 \mathrm{~h}_{\mathrm{f}}+\rho_{\mathrm{c}} \cdot \mathrm{h}_{\mathrm{c}}=2 \times 0.01+0.011161 \times 0.18=0.02200898 \mathrm{~m} \\
& \mathrm{M}_{\mathrm{e}}=7850 \times(0.02200898) \\
& \mathrm{M}_{\mathrm{e}}=172.770493 \mathrm{~kg} / \mathrm{m} 2
\end{aligned}
$$


Using MATLAB program [7] and the equations listed above, the natural frequencies and the mode shape of the equivalent plate can be computed. Table (2) displays the computed natural frequencies in $\mathrm{rad} / \mathrm{sec}$, Figure (6) shows the 3D first mode shape for the plate. Figure (7) show the first mode shape in $\mathrm{x}$ and $\mathrm{y}$ direction for two mode. Figure (8) shows the 3D second mode shape for the plate. Figure (9) shows the second mode shape in $\mathrm{x}$ and $\mathrm{y}$ direction for two modes.

\subsection{Forced Vibration of the Plate:}

Consider the plate shown in figure (5) subjected to a uniformly distributed dynamic load, $p(t)$. The general expression for deflected shape may be taken as [8]:

$z=\sum_{j=1}^{\infty} \sum_{i=1}^{\infty} A_{j i} \sin \frac{j \pi x}{a} \sin \frac{i \pi y}{b}$

where:

$A_{j i}$ : The modal ordinate at the center of the plate.

Equation (14) obviously satisfies the boundary conditions:

At edge $\mathrm{x}=0$ or $\mathrm{x}=\mathrm{a}$

$\mathrm{z}=0 \quad, \quad \frac{\partial^{2} \mathrm{z}}{\partial \mathrm{x}^{2}}=0$

At edge $\mathrm{y}=0$ or $\mathrm{y}=\mathrm{b}$

$\mathrm{z}=0 \quad, \quad \frac{\partial^{2} \mathrm{z}}{\partial \mathrm{y}^{2}}=0$

Each possible combination of integer values of $\mathrm{j}$ and $\mathrm{i}$ define a modal shape. In the following only the first mode will be considered, that is $(\mathrm{j}=\mathrm{i}=1)$, but the method of extension to higher modes will be apparent. Thus the shape function is:

$z=A_{1} \sin \frac{\pi x}{a} \sin \frac{\pi y}{b}$

And using the Lagrange's equation

$\frac{\mathrm{d}}{\mathrm{dt}}\left(\frac{\partial \mathrm{K}}{\partial \dot{\mathrm{A}_{1}}}\right)+\frac{\partial \mathrm{U}}{\partial \mathrm{A}_{1}}=\frac{\partial \mathrm{W}_{\mathrm{e}}}{\partial \mathrm{A}_{1}}$

The modal equation of motion can be obtained.

where:

$\mathrm{K}$ : The kinetic energy.

$U$ : The strain energy. $W_{e}$ : The external work. 


\subsubsection{Kinetic energy of the plate:}

Since the kinetic energy of any element of the plate is given by

$d K=1 / 2 m \dot{z}^{2} d x d y$

where $\mathrm{m}$ is the mass per unit area, The total kinetic energy obtained by integration over the plate area will be

$K=1 / 2 m \int_{0}^{b} \int_{0}^{a}\left(\dot{A_{1}} \sin \frac{\pi x}{a} \sin \frac{\pi y}{b}\right)^{2} d x d y=1 / 8 m \dot{A}_{1}{ }^{2} a b$

Therefore

$\frac{d}{d t}\left(\frac{\partial K}{\partial \dot{A_{1}}}\right)=1 / 4$ ma $b \ddot{A_{1}}$

\subsubsection{Strain energy of the plate:}

The total strain energy by conventional plate theory is

$\mathrm{U}=\frac{\mathrm{D}}{2} \int_{0}^{\mathrm{b}} \int_{0}^{\mathrm{a}}\left[\left(\frac{\partial^{2} \mathrm{z}}{\partial \mathrm{x}^{2}}\right)^{2}+\left(\frac{\partial^{2} \mathrm{z}}{\partial \mathrm{y}^{2}}\right)^{2}+2 \vartheta \frac{\partial^{2} \mathrm{z}}{\partial \mathrm{x}^{2}} \frac{\partial^{2} \mathrm{z}}{\partial \mathrm{y}^{2}}+2(1-\vartheta)\left(\frac{\partial^{2} \mathrm{z}}{\partial \mathrm{x} \partial \mathrm{y}}\right)^{2}\right] \mathrm{dx} \mathrm{dy}$

Operating in equation (12) give:

$\frac{\partial^{2} z}{\partial x^{2}}=-A_{1} \frac{\pi^{2}}{a^{2}} \sin \frac{\pi x}{a} \sin \frac{\pi y}{b}$

$\frac{\partial^{2} z}{\partial y^{2}}=-A_{1} \frac{\pi^{2}}{b^{2}} \sin \frac{\pi x}{a} \sin \frac{\pi y}{b}$

$\frac{\partial^{2} z}{\partial x \partial y}=+A_{1} \frac{\pi^{2}}{a b} \cos \frac{\pi x}{a} \cos \frac{\pi y}{b}$

By substituting these expressions and integrating, the strain energy will be

$U=\frac{\pi^{4} a b D}{8} A_{1}^{2}\left(\frac{1}{a^{2}}+\frac{1}{b^{2}}\right)^{2}$

\subsubsection{External work by a uniformly distributed load:}

$W_{e}=p(t) \int_{0}^{b} \int_{0}^{a} A_{1} \sin \frac{\pi x}{a} \sin \frac{\pi y}{b} d x d y$ 
$W_{e}=p(t)\left(\frac{4 a b}{\pi^{2}}\right) A_{1}$

\subsubsection{Modal equation of motion:}

By substituting these expressions into the Lagrange equation (Eq.18) yields the modal equation of motion in the form:

$\ddot{A_{1}}+\frac{\pi^{4} D}{m}\left(\frac{1}{a^{2}}+\frac{1}{b^{2}}\right)^{2} A_{1}=p(t)\left(\frac{16}{m \pi^{2}}\right)$

The parables of the second term is the same as the square natural frequency obtained in equation (8). By considering the numerical example mentioned in section (3.2) with the uniformly pressure time function as displayed in figure (10).

$\left(\right.$ Pressure $=1.158319 \mathrm{MPa}=118115.7 \mathrm{~kg} / \mathrm{m}^{2}$ )

$p(t)=118115.7 f(t)$

Substitution the numerical values into the modal equation of motion provide:

$\ddot{A_{1}}+\frac{\pi^{4}(19910.6913)}{172.770493}\left(\frac{1}{(2.6)^{2}}+\frac{1}{(1.4)^{2}}\right)^{2} A_{1}=p(t)\left(\frac{16}{(172.770493) \pi^{2}}\right)$

$\ddot{A_{1}}+4862.322 A_{1}=0.009383 p(t)$

Or

$\ddot{A_{1}}+4862.322 A_{1}=1108.2796131 f(t)$

Therefore: the natural frequency of the first mode

$\omega_{1}=\sqrt{4862.322}=69.7304 \mathrm{rad} / \mathrm{sec}$

And natural period of vibration

$T_{1}=\frac{2 \pi}{\omega_{1}}=\frac{2 \pi}{69.7304}=0.0901 \mathrm{sec}$

This result it is the same as that obtained in section (3.1)

The modal static deflection $A_{n s t}$ is obtained as:

$A_{1 s t}=\frac{1108.2796131}{4862.322}=0.228 \mathrm{~m}$

By converting the DLF curve mentioned in TM5 into polynomial of order ten versus (X): The dynamic load factor DLF can be obtained by the following equation with $X=\log \left(T_{d} / T_{n}\right)$, and $\left(\mathrm{T}_{\mathrm{d}} / \mathrm{T}_{\mathrm{n}}\right) \in[0.01,10]$ 


$$
\begin{array}{rl}
\mathrm{DLF}=1.55 & 48175+0.93410619 \mathrm{X}-0.97345425 \mathrm{X}^{2}+0.19406748 \mathrm{X}^{3} \\
& +1.0987185 \mathrm{X}^{4}-0.47307345 \mathrm{X}^{5}-0.8972641 \mathrm{X}^{6} \\
& +0.053293176 \mathrm{X}^{7}+0.33868533 \mathrm{X}^{8}+0.11759425 \mathrm{X}^{9} \\
& +0.010565044 \mathrm{X}^{10}
\end{array}
$$

Using equation (37) with $\frac{t_{d}}{T_{1}}=\frac{0.00928}{0.0901}=0.103 \stackrel{\text { yields }}{\longrightarrow} \mathrm{DLF}=0.3198636$

The maximum dynamic deflection at the center of the equivalent plate is therefore

$$
y_{\max }=\left(A_{1}\right)_{\max }=A_{1 s t}(D L F)=0.228 \times 0.3198636=0.073 \mathrm{~m}
$$

\subsection{Calibration with FEM and Design Experimental Application (DOE):}

For verification purposes, three cases of simply supported solid panel were analyzed firstly with the mathematical equations listed above using APDL-DOE [9], and secondly with FEM [1] and the results were listed in table (3). The table shows that the results obtained using APDL-DOE and FEM is very satisfied with error less than 5\%. This method easily predicted the maximum deflection response of the honeycomb panel by converting the honeycomb to solid plate. Table (4) shows the initial input value for (DOE). Table (5) shows the output values for DOE and FEM due to initial values. Figure (11) shows the test model of the hexagonal sandwich panel used in FEM. And Fgure (12) shows the response of the tested panel versus time. Figure (13) shows the 3D-Plot of response surface (relative density, pressure, deflection) obtained using DOE program. The figure show that the maximum displacement obtained at minimum relative density and maximum pressure. Figure (14) shows the 3D-Plot of response surface (relative density, dimension ratio, deflection). It can be noted that the increasing of relative density and dimension ratio causes decreasing in displacements.

\subsection{Scaling Dimensional of the Sandwich}

This section considers the techniques for creating suitably scaled models of the panel structure for assessment of response due to blast loading.

Consider a specific example of a blast loaded panel idealized as an elastically supported lumped mass as shown in figure (15):

By applying the Rayleigh's method, the behavior might be assessed as the follows:

Characteristic the response by maximum displacement, $\mathrm{Y}_{\max }$, this depends on :

Panel mass $M$, spring stiffness $K$, peak applied loading $\mathrm{P}^{*}$, duration of loading $\mathrm{T}_{\mathrm{d}}$.

Thus the maximum displacement $Y_{\max }$ occurred only one time through the positive duration Td or through the first mode of vibration:

$$
Y_{\text {max }}=A M^{\alpha_{1}} K^{\beta_{1}} P^{* \gamma_{1}} T_{d}^{\delta_{1}}+B M^{\alpha_{2}} K^{\beta_{2}} P^{* \gamma_{2}} T^{\delta_{2}}+\cdots
$$

In dimensional terms: 


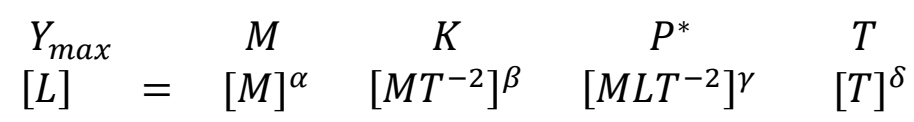

So, equating dimensional powers

$M: 0=\alpha+\beta+\gamma$

$L: 1=\gamma$

$T: 0=-2 \beta-2 \gamma+\delta$

4 unknowns but only 3 equations, therefore $\operatorname{select}(\alpha)$ to solve $(\beta \gamma \delta)$ in terms of $(\alpha)$. Solving $\stackrel{\text { yields }}{\longrightarrow}$

$$
\gamma=1, \quad \beta=-\alpha-1 \text { and } \delta=-2 \alpha
$$

Thus, in its simplest form the original equation may be written

$Y_{\max }=A \quad M^{\alpha} K^{-1-\alpha} P^{*-1} T^{-2 \alpha}$

Group together parameters with exponent, $(\alpha)$

$$
Y_{\max }=A\left[\frac{M}{K T^{2}}\right]^{\alpha}\left[\frac{P^{*}}{K}\right]
$$

Buckingham's theorem also indicates $[\mathrm{N}-\mathrm{n}]=[5-3]=2 \Pi$ numbers.

where: $\mathrm{N}$ is an independent parameters and $\mathrm{n}$ is primary quantities.

So select $(\alpha)$, so that $(\mathrm{M})$ will only appear once in any $\Pi$ numbers set.

This may be written as $\Pi$ numbers in the form

$$
\begin{aligned}
& \frac{Y_{\max } K}{P^{*}}=A\left[\frac{M}{K T^{2}}\right]^{\alpha}=f\left[\frac{M}{K T^{2}}\right] \quad--\rightarrow \quad \text { named } K_{1} \\
& \frac{Y_{\max } K}{P^{*}}=A\left[\frac{M}{K T^{2}}\right]^{\alpha}=f\left[\frac{M}{K T^{2}}\right]=f\left[\frac{\text { Area } \times M_{e}}{K T^{2}}\right]-\rightarrow \text { named } K_{2}
\end{aligned}
$$

Figure (16) shows the design chart represents the relationship diagram for steel panel with area $\left(\mathrm{A}: \mathrm{m}^{2}\right)$ with out-of-plane maximum deflection response has been measured as a function of the relative density and time duration. The peak deflection is relatively to time duration and inversely proportioning to the relative density of the specimen. Figure (16) is shown to be in approachable quick chosen to the relative density of the panel which gives the designer with effortlessness the estimation of the initial design of the panel subjected to blast loads or for estimating the resistance of the prefabricated sandwich panels or for using to estimate the initial values for the optimization technique. 


\section{Conclusion}

- Converting the charts provided by TM5 into tenth order polynomials for the peak pressure and positive duration, provides an easy method to predict the transient blast loads resulting from detonating any spherical TNT charge at any distance.

- The study shows that the results obtained using theoretical procedure based on (DOE) and FEM is very satisfactory (the error is less than 5\%). using an equivalent solid plate to a honeycomb panel is an easy way to predicted the maximum response of the honeycomb panel.

- Design chart obtained using the scaling dimensional of the sandwich panel easy to be in approachable quick chosen to the relative density of the panel which gives the designer with effortlessness the estimation of the initial design of the panel subjected to blast loads. And for estimating the resistance of the prefabricated sandwich panels or for using into estimating the initial values for the optimization technique.

\section{References}

[1] El-fayad. H. M, Abdel-Wahab.M. M, Farag . H. M. And El-ashaal. A. A,” Optimum Design for Sandwich Panels with Metallic Hexagonal Honeycomb Core Subjected to Blast Loads". Proceedings of the $7^{\text {th }}$ International Conference on Civil \& and Arch. Eng, ” Egypt, (2008), pp. 87-105.

[2] TM5, "Structures to Resist The Effects of Accidental Explosion”, USA (1990).

[3] ANSYS “Theory Reference manual”, ANSYS Inc.

[4] Manual for AUTODYN software Agency of Century Dynamics Company (2003).

[5] Yang, Bengen. "Stress, Strain, and Structural Dynamics", University of Southern California, (2004).

[6] Jeom Kee Paik, Anil K. Thayamballi, Gyu Sung Kim, "The Strength Characteristics of Aluminum Honeycomb Sandwich Panels", Pusan National University, south Korea (1999).

[7] MATLAB Programming. "The Language of Technical Computing", Ver.7.

[8] John M. Biggs. "Introduction to Structural Dynamics", Massachusetts Institute of Technology, USA, ISBN: 07-005255-7,(1964).

[9] ANSYS Workbench ${ }^{\mathrm{TM}}$, USA (2007).

Table 1 Comparison Between TM5 Code and Present Polynomials

\begin{tabular}{|c|c|c|c|c|}
\hline \multirow{2}{*}{$\mathrm{Z}$} & \multirow{2}{*}{ parameter } & \multirow{2}{*}{ TM5 } & Present & \multirow{2}{*}{ error $\%$} \\
\hline & & & Polynomials & \\
\hline \multirow{2}{*}{2.715454} & [psi] & 114.8112 & 114.8106 & 0.000523 \\
\hline & $\mathrm{T}_{\mathrm{d}} / \mathrm{W}^{1 / 3} \quad\left[\mathrm{~ms} / \mathrm{lb}^{1 / 3}\right]$ & 1.400213 & 1.399885 & 0.023430 \\
\hline \multirow{2}{*}{1} & [psi] & 844.7594 & 844.7628 & 0.000402 \\
\hline & $\mathrm{T}_{\mathrm{d}} / \mathrm{W}^{1 / 3} \quad\left[\mathrm{~ms} / \mathrm{lb}^{1 / 3}\right]$ & 0.1734818 & 0.1736322 & 0.086620 \\
\hline \multirow{2}{*}{50} & [psi] & 0.6528669 & 0.6528662 & 0.000107 \\
\hline & $\mathrm{T}_{\mathrm{d}} / \mathrm{W}^{1 / 3} \quad\left[\mathrm{~ms} / \mathrm{lb}^{1 / 3}\right]$ & 3.941886 & 3.943845 & 0.049697 \\
\hline \multirow{2}{*}{4} & [psi] & 47.59982 & 47.59979 & 0.000063 \\
\hline & $\mathrm{T}_{\mathrm{d}} / \mathrm{W}^{1 / 3} \quad\left[\mathrm{~ms} / \mathrm{lb}^{1 / 3}\right]$ & 1.288972 & 1.288724 & 0.019240 \\
\hline
\end{tabular}


Table 2 Natural Frequencies $\omega_{\mathrm{mn}}$ of the Proposed Plate [rad/sec]

\begin{tabular}{|c|c|c|c|c|}
\hline $\mathrm{n} m$ & 1 & 2 & 3 & 4 \\
\hline 1 & 69.7 & 231.9 & 502.2 & 880.6 \\
\hline 2 & 116.8 & 278.9 & 549.2 & 927.6 \\
\hline 3 & 195.1 & 357.3 & 627.6 & 1006 \\
\hline 4 & 304.8 & 467 & 737.3 & 1115.7 \\
\hline
\end{tabular}

Table 3 Response Comparison of Simply Supported Solid Panel in DOE and FEM

\begin{tabular}{|c|c|c|c|c|c|c|c|c|}
\hline case & $\begin{array}{c}\text { Pressure } \\
\text { bar }\end{array}$ & $\begin{array}{c}\text { Relative } \\
\text { Density } \\
\mathrm{kg} / \mathrm{m} 2\end{array}$ & $\begin{array}{c}\text { AREA } \\
\mathrm{M}^{2}\end{array}$ & $\begin{array}{c}\text { Aspect } \\
\text { ratio }\end{array}$ & $\begin{array}{c}\text { Duration } \\
\mathrm{sec}\end{array}$ & $\begin{array}{c}\text { Deflection } \\
\text { APDL-DOE }\end{array}$ & $\begin{array}{c}\text { Deflection } \\
\text { FEM }\end{array}$ & $\begin{array}{c}\text { Error } \\
\%\end{array}$ \\
\hline 1 & 11.58319 & 170.69825 & 2.879831 & 1.5 & 0.00928 & 0.065 & 0.062 & 4.61 \\
\hline 2 & 11.58319 & 170.69825 & 2.6878423 & 1.4 & 0.00928 & 0.062 & 0.061 & 1.61 \\
\hline 3 & 11.58319 & 170.69825 & 1.92 & 1 & 0.00928 & 0.047 & 0.049 & 4.08 \\
\hline
\end{tabular}

Table 4 Initial Values for DOE

\begin{tabular}{|l|c|l|c|}
\hline Item & value & E: young's modulus, $[\mathrm{pa}]$ & $2 \times 10^{11}$ \\
\hline $\mathrm{P}_{0}[\mathrm{bar}]$ & 11.58319 & $\vartheta$ : Poisson's ratio & 0.3 \\
\hline Relative density $\left[\mathrm{kg} / \mathrm{m}^{2}\right]$ & 188.83603 & $l:$ Wall core length, $[\mathrm{m}]$ & 0.11547 \\
\hline Area $\left[\mathrm{m}^{2}\right]$ & 3.2641016 & density of the material, $\left[\mathrm{kg} / \mathrm{m}^{3}\right]$ & 7850 \\
\hline Dimension ratio & 1.9147688 & Wall core thickness, $[\mathrm{m}]$ & 0.001 \\
\hline Duration, $[\mathrm{sec}]$ & 0.00928 & Plate thickness, top or bottom), $[\mathrm{m}]$ & 0.01 \\
\hline
\end{tabular}

Table 5 Output Values for DOE and FEM Due to Initial Values

\begin{tabular}{|c|c|}
\hline Item & value \\
\hline Max.displacement [m], using APDL & 0.0531 meter \\
\hline \multirow{2}{*}{ Max.displacement [m], using FEM } & 0.0532142 meter back plate \\
\cline { 2 - 2 } & 0.0531908 meter front plate node 42587 \\
\hline
\end{tabular}




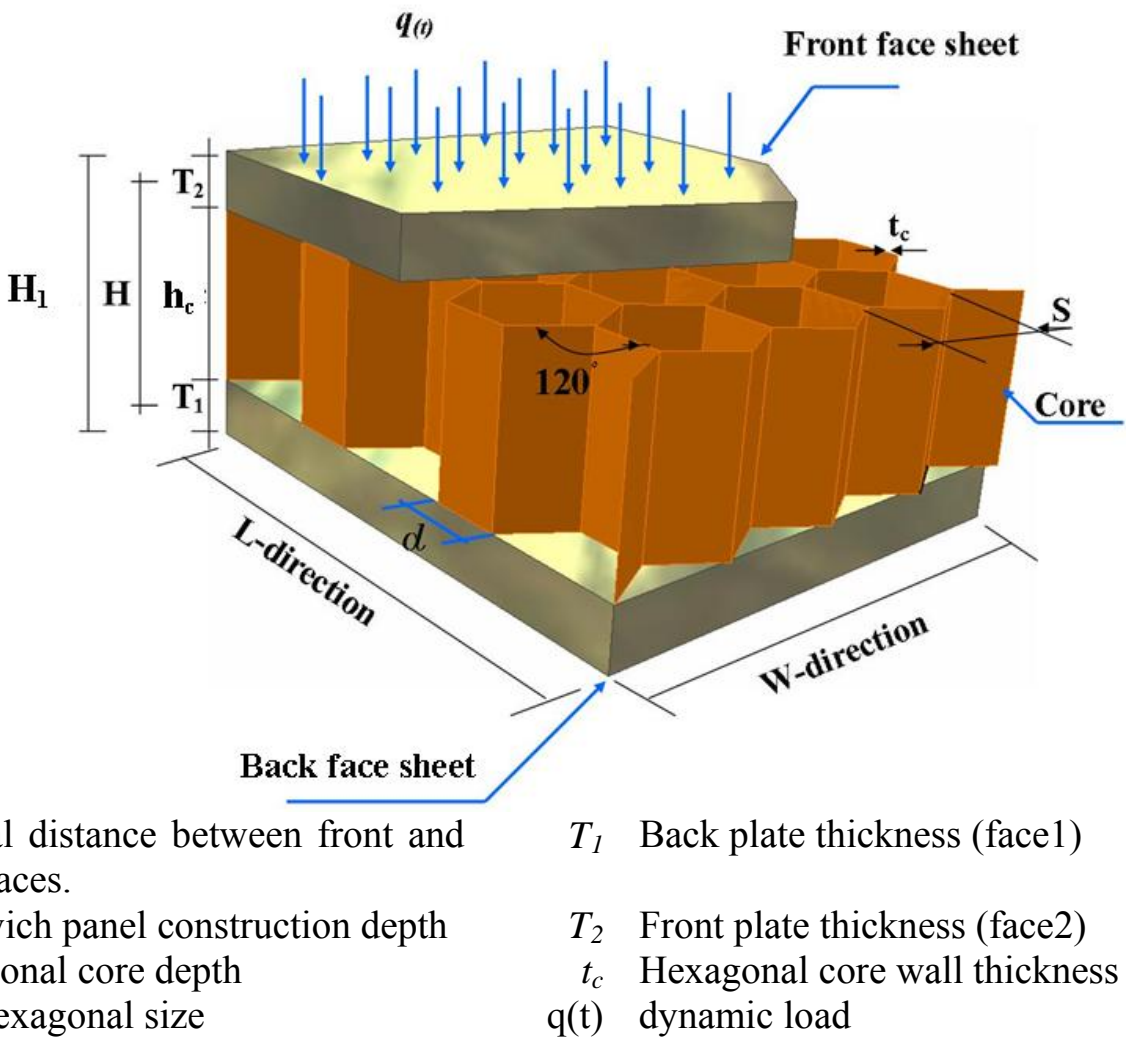

Fig. 1 Typical Hexagonal Honeycomb Core Sandwich Panel.

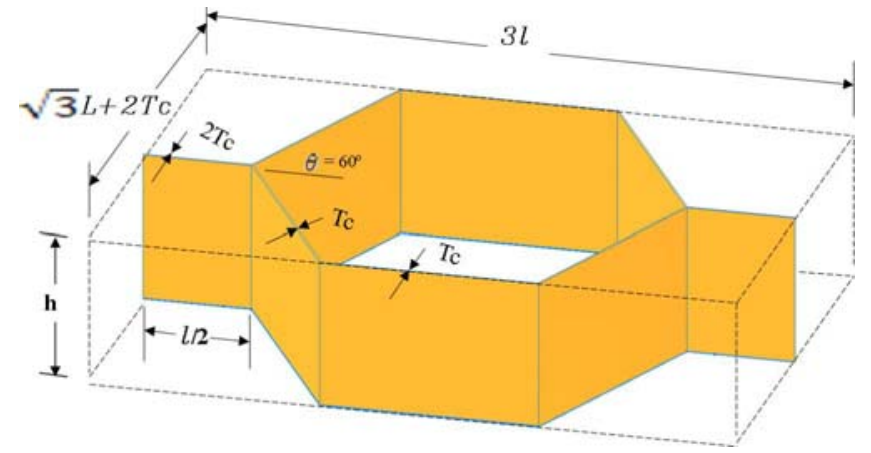

Fig. 2 Typical Regular Hexagonal Honeycomb Core. 


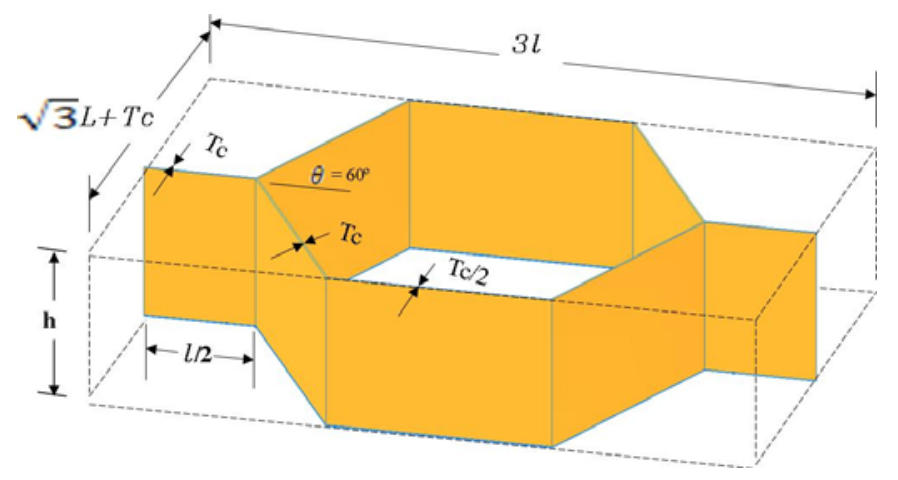

Fig. 3 Typical un Regular Hexagonal Honeycomb Core

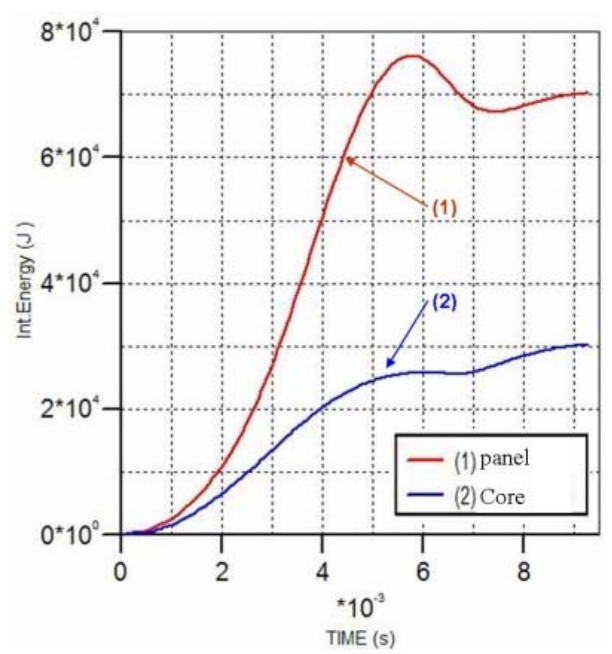

Fig. 4 Internal Energy Absorbed By Hexagonal Core \& Panel.[1]

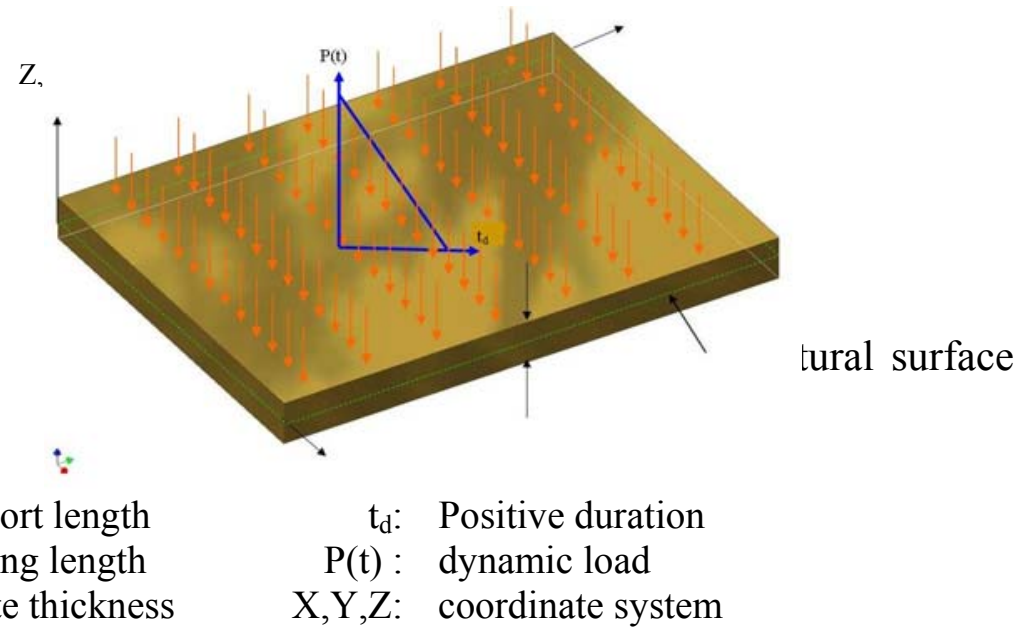

Fig. 5 A Rectangular Plate in Transverse Vibration 


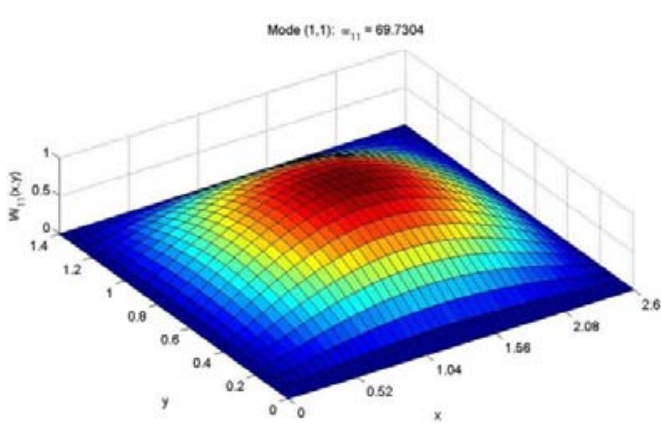

Fig. 6 3D Plot for Mode Shape $\omega_{1,1}$

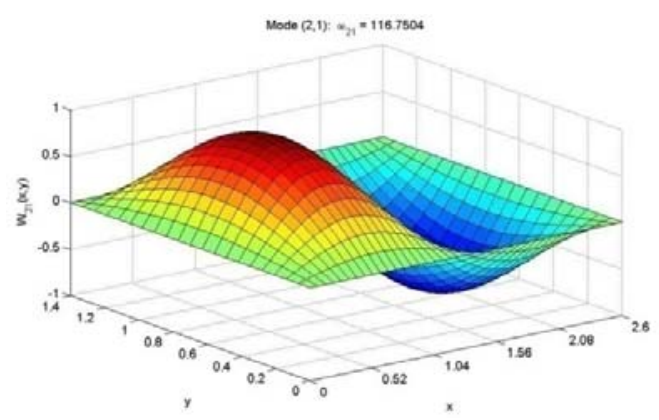

Fig. 8 3D Plot for Mode Shape $\omega_{1,2}$

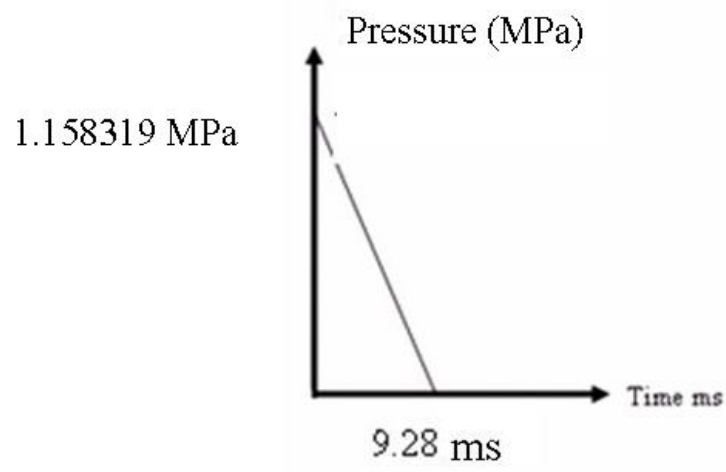

Fig. 10 Pressure Time History For The Numerical Example.
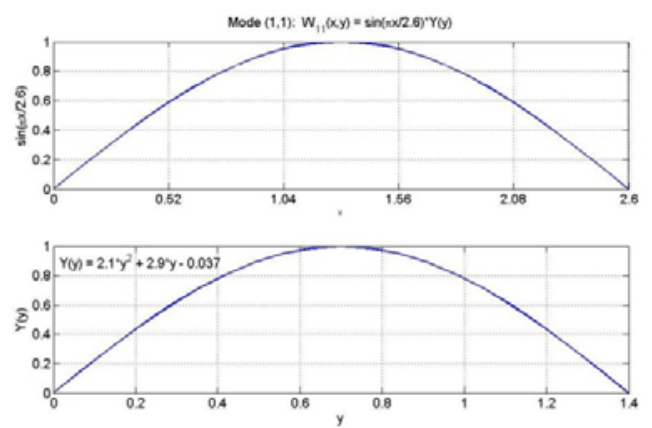

Fig. 7 Plots of the Mode Shape $\omega_{1,1}$ in $x$ and $y$
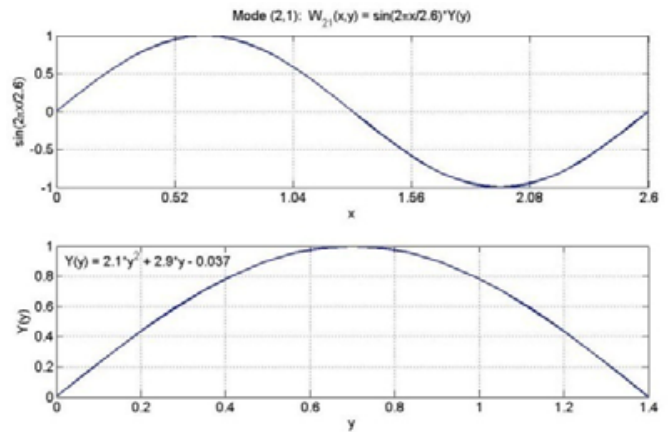

Fig. 9 Plots of the Mode Shape $\omega_{1,2}$ in $x$ and $y$

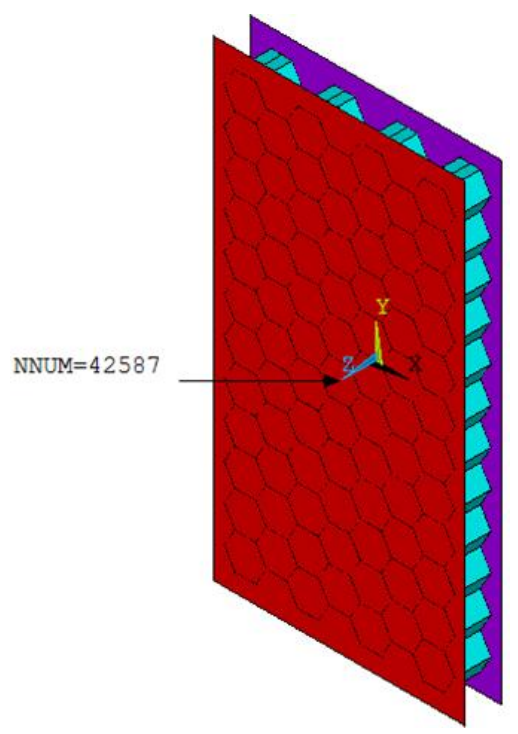

Fig. 11 3D View of the Test Model. 


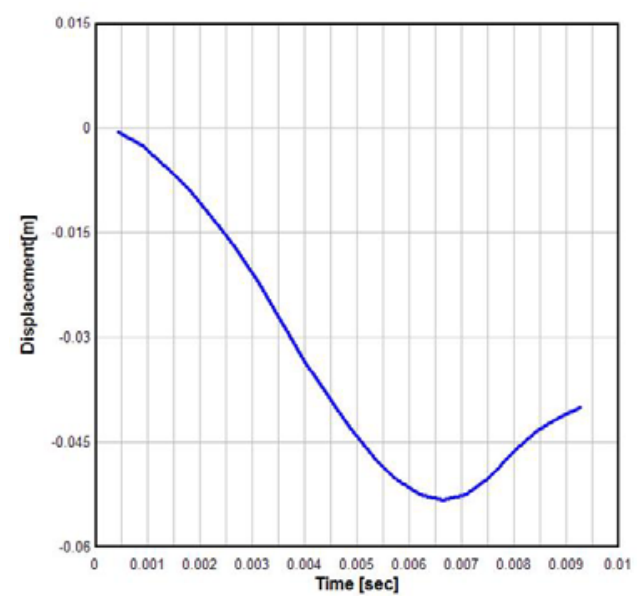

Fig. 12 Displacement Versus Time for Node (42587) Center of the Front Plate.

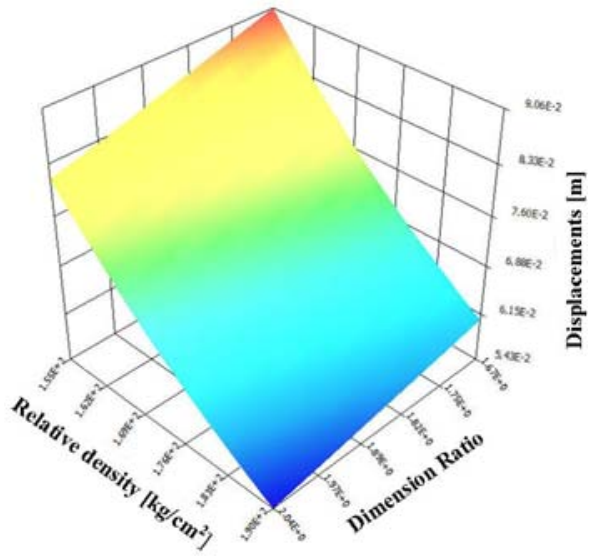

Fig. 14 3D-Plot of Response Surfaces (Relative Density, Dimension Ratio, Deflection).

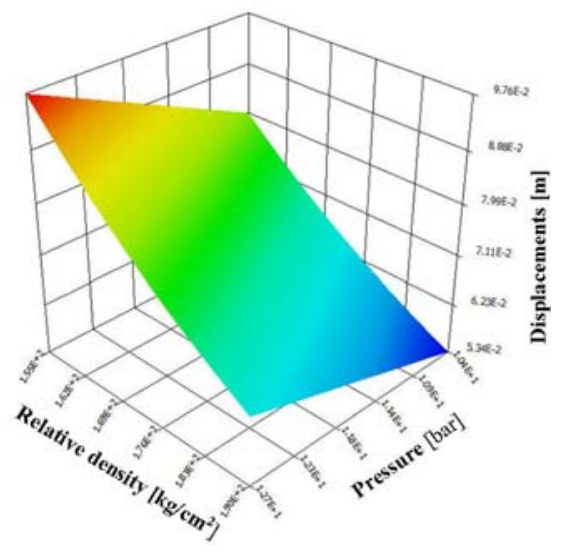

Fig. 13 3D-Plot of Response Surfaces ( Relative Density, Pressure, Deflection)

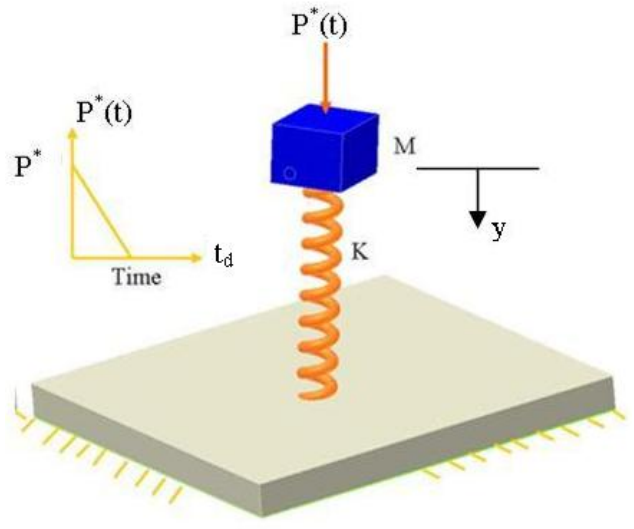

Fig. 15 Equivalent SDOF Model for the Panel

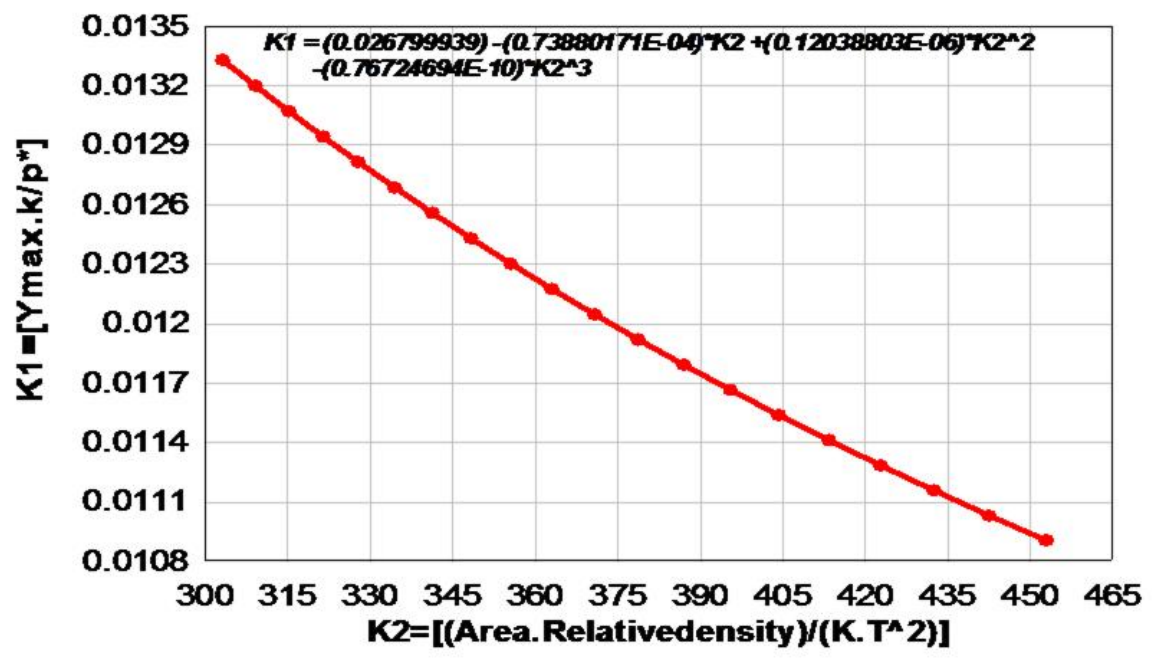

Fig. 16 Non Dimensional Paragraph for k1 @ k2 